\title{
Using the Stages of Concern Questionnaire to Ensure Professional Development with Teachers and Teacher Candidates
}

\author{
Morgan B. Bullard ${ }^{1}$, Chayla D. Rutledge ${ }^{1} \&$ Patricia Kohler-Evans ${ }^{1}$ \\ ${ }^{1}$ University of Central Arkansas, Conway, Arkansas, USA \\ Correspondence: Morgan B. Bullard, University of Central Arkansas, Conway, AR, USA. Tel: 1-870-371-1759.
}

Received: October 26, 2017

Accepted: November 28, 2017

Online Published: December 14, 2017

doi:10.5430/irhe.v2n4p50

URL: https://doi.org/10.5430/irhe.v2n4p50

\begin{abstract}
Classroom instruction is highly influenced by the quality of the professional development that teachers and teacher candidates receive. Instructional interventions at the classroom level must be research-based, and working with teachers and teacher candidates to implement interventions effectively is a daunting task. One way to help ensure professional development is effective involves gauging teachers' and teacher candidates' concerns, using the Stages of Concern Questionnaire (SOCQ) from the Concerns Based Adoption Model (CBAM). In the current study, teacher candidates received professional development at the pre-service level, and teachers received the same professional development at the in-service level. Both groups were taught specific interventions designed to target middle and secondary students using the Strategic Instruction Model Content Enhancement Routines. The SOCQ was administered prior to and following a professional development series that spanned several months. An analysis of results indicated that professional development is effective in reducing concern in both teachers and teacher candidates. Teachers and teacher candidates overall shared similar concerns on some areas yet were different in their levels of concern in other areas. The researchers suggest possible interpretations for the similarities and differences in results and offer areas for future study.
\end{abstract}

Keywords: professional development, levels of concern, intervention implementation, pre-service, in-service, change process

\section{Introduction}

\subsection{Professional Development}

Professional development is a core building block in the advancement and improvement of educators and is widely regarded as a crucial influencing factor in impacting student achievement. Professional development is a set of practices and processes focused on growth in knowledge, skills, and attitudes that are required of teachers and other educators directed toward improved levels of student achievement. Educators at all levels must continually update their knowledge and skill levels for many reasons, yet one stands out among the rest. Considerable evidence supports the conclusion that differences in student achievement can be attributed, in part, to quality professional development, and this assertion is affirmed in numerous studies with multiple grade levels and content areas (Miller, Curwen, White-Smith, \& Calfee, 2015; Abika \& Liang, 2016; Martin, McCaughtry, Hodges-Kulinna, \& Cothran, 2008; Kutaka, Smith, Albano, Edwards, Ren, Beattie, \& Stroup, 2017).

As stated, classroom instruction is often influenced by the quality of the professional development teachers receive. Choosing what professional development to provide is dependent, in part, on the recent onslaught of interventions with emphasis on research-based, evidence-based practice, a focus on standards such as the Common Core State Standards (Common Core State Standards Initiative, 2017), and high-stakes assessment results. When deciding how to provide professional development, as well as what professional development is needed and offered, it becomes even more imperative that all educators receive the professional development that considers the needs of all stakeholders, which includes teachers, as well as their students.

Professional development is generally provided prior to employment (pre-service) and after employment (in-service). Whether professional development is provided at the pre-service or in-service level, guiding practices can enhance the experiences, thus leading to improved student achievement. Positive change is possible when educators, administrators, and those who provide professional development focus on teachers' or teacher candidates' needs, 
characteristics, strengths, goals for growth, and previous experiences.

Frequently, when teachers are faced with the task of implementing a new intervention, they come to the process of change. The process of change is a developmental process and teachers will vary in the stages they are in. Some will go through the process faster than others. Teachers can also be in multiple stages at once. There are some who are familiar with the intervention, some who have never heard of the intervention, and some who have varying degrees of experience with the intervention. For those who work with teachers, facilitating and leading the process of intervention implementation can be met with excitement, frustration, or even anger at the suggestion of something new or different being tried. (Knight, 2007) It is critical that those who provide professional development are keenly aware of how those responsible for implementation at the classroom level (the teachers) are receiving the professional development and implementing the intervention with fidelity. This can be a daunting task for both those who are learning and those who are delivering instruction in the intervention through pre-service or in-service professional development.

Based on many years of experience in working with Arkansas educators, both at the pre-service and in-service level, several non-negotiable practices are recommended by Kohler-Evans, Calhoon, \& Cooper (2014). These practices have been cultivated, applied, and refined in concert with the provision of over ten years of professional development throughout the state. The non-negotiable practices, when applied, have resulted in successful implementation of interventions with students in Arkansas. The non-negotiables are: seek collaboration vs coexistence, individualize service, and provide high quality professional development that is data driven, engaging, and inclusive of coaching and fidelity checks (Kohler-Evans, Calhoon, \& Cooper, 2014). Inherent in all the practices is the importance of understanding and responding to educators, wherever they happen to be, regarding the implementation of an intervention designed to positively impact student achievement.

\subsection{Concerns Based Adoption Model}

In the present study, the impact of professional development is evaluated by the level of concern exhibited by preand post-tests on the Stages of Concern Questionnaire. The Stages of Concern Questionnaire (SOCQ), from the Concerns Based Adoption Model (CBAM) framework, has been used for measuring implementation of practices and facilitating change. Using the SOCQ to help professional developers understand how teachers fall on a continuum of concern is one way to facilitate implementation of an intervention. In addition to assisting educators in understanding the myriad elements of the change process, the CBAM SOCQ can be used to ensure that professional development activities and processes will help increase the likelihood that student success will be positively impacted. For those who engage in planning and delivering professional development to classroom teachers, it is imperative that an understanding of participants, their concerns and their level of readiness, are each understood and folded into the delivery of the professional development activities. The SOCQ provides a means of understanding where teachers fall on a continuum that spans from the awareness stage (gaining interest in the intervention) through the refocusing stage (concentrating on new developments and interests beyond the current intervention). In the current study, the SOCQ was administered to assist the professional development team in providing high quality professional development to educators learning and implementing a research-validated methodology targeting students with diverse needs in grades 4-12.

The CBAM collectively provides a framework for measuring the application and utilization of change inducing tools or procedures in order to facilitate lasting effective development. Through this model, educators can grow in their understanding of how they respond to both change itself, and the processes of change as a whole. By gaining an understanding of both the change and the process of change, the CBAM model allows assurance that potential actions can be taken to facilitate successful change, and professional development activities, with the greatest potential impact, can be provided to those who are receiving the professional development (PD). Using the framework provided by the Concerns Based Adoption model increases the chances that the person(s) undergoing change will be positively impacted by professional development and systematic change (Saunders, 2012).

According to George, Hall, and Stiegelbauer (2006), "the CBAM research team believed that change begins with the individual, usually the teacher or adopter, and focused its early efforts on understanding what happens to teachers and college faculty when presented with a change" (pg. 1). The CBAM consists of three diagnostic dimensions: the Innovation Configuration, the Levels of Use, and the Stages of Concern. The implementation of the Concerns Based Adoption Model in this study focuses on the Stages of Concern Questionnaire, but exploring the other two dimensions is necessary to understand a complete overview of the appropriate application and utilization of this model.

Often times, educators spend a considerable amount of time learning new or evolving school programs and practices, 
but they are left lacking when it comes to the practical application. Educators are often taught what a program is. They are not taught what it looks like carried out in real time. The diagnostic area of Innovation Configuration addresses this by providing expectations, descriptions, and guides for each individual person involved in the program. By using this tool, every educator that the program affects is able to see a clear depiction of what the program looks like from their particular stance. With this comes Innovation Configuration maps that chart out the distinct ways a person may go about implementing the program or practice in a functional pragmatic way.

Levels of Use is another section of the Concerns Based Adoption Model that is useful at the individual change level. The Levels of Use consists of an interview tool that informs educators of how both, themselves and others are realistically using a program. To accomplish this, the diagnostic tool encompasses eight levels that depict where an educator is in implementing a change by their current actions regarding the program. Multiple brief interviews are conducted to confer an individual's ongoing level of use. The levels are as follows: non-use, orientation, preparation, mechanical use, routine use, refinement, integration, and renewal.

The diagnostic CBAM tool used in the methodology of this study is pulled from the third category: Stages of Concern. The Stages of Concern Questionnaire (SOCQ) was initially used for the purposes of evaluating teachers, and was developed in the 1970's by Hall and Loucks. The SOCQ was designed to look primarily at trainee concerns and the affective experience of change. The Stages of Concern as a full unit includes a questionnaire, interview, and open-ended statements to measure an individual educator's beliefs and position regarding the implementation of change. As described by Bailey and Palsha (1992), the Stages of Concern assumes that change is an ongoing, personal development that is mediated by training and can be matched to the expressed concerns of the individuals. The Stages of Concern consists of seven distinct categories: awareness, informational, personal, management, consequence, collaboration, and refocusing. Thus, questions arise such as: "Is the educator ready to make a change? What are the educator's personal thoughts on the program or practice? Is the educator uncomfortable with the change process all together?" These types of questions and feelings are worked through to identify where the educator stands. The overarching theoretical idea is that the further along in the seven Stages of Concern categories an educator moves, is correlated with an increasing likelihood that an effective change will occur.

The Stages of Concern Questionnaire is a thirty-five item questionnaire that functions to categorize and assess concerns surrounding potential change in programs and practices. The individual taking the questionnaire will fall into one of the six categories above (awareness, informational, personal, management, consequence, collaboration, refocusing) by being scored on their responses to the questions found in the SOCQ. If an individual falls into a category such as collaboration or refocusing, they are likely to have less concern about the implementation of the new program or practice. On the other end of the spectrum, scores that fit into the informational or personal categories would indicate more concern from the individual regarding the change. The findings generated by Charalambos and Philippou (2010) in a study exploring teachers' concerns and beliefs about implementation of a mathematics program in school, supports the basic ideas surrounding the assumptions made about the importance of change and the concerns that come along with it. The researchers found that teachers who were more comfortable with pre-reform approaches (programs and practices currently in place), tended to be more critical of the new reform and their capacity to handle it. It was also found that they were more anxious about the impact the reforms would have on student learning. This suggests that reforms may fail if teachers' beliefs about this do not improve.

Change and reform are associated with raising teacher quality, improving student learning, student achievement, and student preparedness, thus it is important that teachers receive the systematic and sustained support to move out of their comfort zone and implement a program or practice (Christesen and Turner, 2014). Using the SOCQ allows for the identification of where the individual's sentiment is in their stance toward the change can occur, and proper actions can be determined to facilitate action. Table 1 outlines the common thoughts and recommended action for each stage of concern. 
Table 1. Stages of concern

\begin{tabular}{|c|c|c|}
\hline $\begin{array}{l}\text { Stage of } \\
\text { Concern }\end{array}$ & Common Thoughts & Recommended Action \\
\hline $\begin{array}{l}0: \\
\text { Awareness }\end{array}$ & $\begin{array}{l}\text { Not concerned with change. Does not have full } \\
\text { concept of the program. Is not interested in } \\
\text { implementation. }\end{array}$ & $\begin{array}{l}\text { Bringing attention to the material, } \\
\text { emphasizing its importance, and generating } \\
\text { interest. }\end{array}$ \\
\hline $\begin{array}{l}\text { 1: } \\
\text { Informational }\end{array}$ & $\begin{array}{l}\text { Begins to show interest. Would like to know more } \\
\text { about it and how it works. }\end{array}$ & $\begin{array}{l}\text { Providing open access to precise, quality } \\
\text { information. }\end{array}$ \\
\hline $\begin{array}{l}\text { 2: } \\
\text { Personal }\end{array}$ & $\begin{array}{l}\text { Begins to think about how a change would directly } \\
\text { affect themselves, as educators. }\end{array}$ & $\begin{array}{l}\text { Continue to provide information. Build } \\
\text { rapport with individuals. Provide } \\
\text { encouraging affirmations. }\end{array}$ \\
\hline $\begin{array}{l}\text { 3: } \\
\text { Management }\end{array}$ & $\begin{array}{l}\text { Begins to think about the time needed to prepare } \\
\text { and begins preparation. Begins to think about } \\
\text { resources needed and becomes concerned with the } \\
\text { actual application. }\end{array}$ & $\begin{array}{l}\text { Showing how it has already been } \\
\text { implemented. Provide examples of how it } \\
\text { would look for educators and students in the } \\
\text { individual's case. }\end{array}$ \\
\hline $\begin{array}{l}\text { 4: } \\
\text { Consequence }\end{array}$ & $\begin{array}{l}\text { Concerned with how change will directly affect } \\
\text { and impact students. }\end{array}$ & $\begin{array}{l}\text { Provide resources and examples of how it } \\
\text { does work/has worked. Share how change } \\
\text { can be effective. }\end{array}$ \\
\hline $\begin{array}{l}\text { 5: } \\
\text { Collaboration }\end{array}$ & $\begin{array}{l}\text { Becomes interested in sharing the implementation } \\
\text { with others. Would like to see how others are } \\
\text { doing compared to self. }\end{array}$ & $\begin{array}{l}\text { Encourage discussion amongst others about } \\
\text { the the implementation, in hopes that they } \\
\text { will share and potentially learn from one } \\
\text { another. }\end{array}$ \\
\hline $\begin{array}{l}\text { 6: } \\
\text { Refocusing }\end{array}$ & $\begin{array}{l}\text { Exploring ideas of what could be better and how it } \\
\text { could be used in different ways. }\end{array}$ & $\begin{array}{l}\text { Provide further resources on strategies. } \\
\text { Encourage sharing of struggles and } \\
\text { successes with others. }\end{array}$ \\
\hline
\end{tabular}

\section{Method}

\subsection{Participants}

A sample of 32 teachers and teacher candidates were provided with Strategic Instruction Model Content Enhancement Routines (SIM CER) professional development. A teacher candidate is defined as an individual who is still undergoing instruction (whether college level or post), but is not yet licensed independently as a teaching instructor. A teacher is defined as a licensed teaching professional with more than two years of teaching experience. Both teachers and teacher candidates received the same SIM CER professional development. Out of the participants, 23 were female, 6 were male, and 3 chose not to disclose. Teachers were also asked to report the amount of time they have been teaching overall. 4 teachers reported 2-5 years, 3 reported 5-10 years, 5 reported 10-15 years, 2 reported 15-20 years, and 8 reported 20+ years of teaching experience. 4 teachers chose not to answer. Out of the complete pool of Stages of Concern Questionnaires that were given, all 32 participants reported that they had never been involved with professional development in the Strategic Instruction Content Enhancement Routines. Eleven participants reported teaching kindergarten through sixth grade (K-6), and seven participants reported teaching seventh grade through twelfth grade (7-12). There were also two participants that reported currently being administrators, one participant reported being a special-education teacher, and five reported not applicable or chose not to answer. The remaining six participants were students in the teacher candidate category. Participants were asked to complete surveys before receiving professional development and then again after the professional development cycle was complete. The SIM CER professional development for each group was provided by Dr. Patricia 
Kohler-Evans and Renee Calhoon who are certified professional developers within the SIM methodology. The completed pre- and post- surveys focused on use of SIM CER and the effectiveness of professional development. The participants were informed that the information they provided would give instructors feedback on the effectiveness of the PD. Initial sample was $n=32$. Final result sample size was $n=22$. The researchers believed that participants were lost due to the time constraints and duration of the study.

\subsection{Materials}

The Stages of Concern Questionnaire itself consists of 35 questions set on a likert scale. Participants can rate their experiences as follows: 0 (irrelevant), 1-2 (not true of me now), 3-4 (somewhat true of me now), or 5-7 (very true of me now). These questions evaluate the affective experience of trainees and determine what stage they are likely in. There are 7 stages: Awareness (0), Informational (1), Personal (2), Management (3), Consequences (4), Collaboration (5), and Refocusing (6). The questionnaire has good reliability with a Cronbach's alpha of 0.64-0.83 and good test-retest reliability with a Pearson-r of 0.65- 0.86 (Saunders, 2012).

Strategic Instruction Model (SIM) Content Enhancement Routines (CER) is a specific professional development strategy under the Strategic Instruction Model framework. The SIM is a research-validated comprehensive approach that aims to provide educators with a foundation for organizing classroom content, effective teaching and learning, and facilitating improved student schooling capabilities. Those undergoing the SIM CER professional development are instructed on how to carry out instruction in ways that involve direct partnership with students through routines such as clarifying, framing, recall enhancement, and concept mastery routines. Each SIM routine provides the individual receiving professional development a hands-on way to conceptualize classroom concepts as well as actions to take based upon those. According to the Strategic Instruction Model in Support of Secondary Literacy (2011), the SIM Content Enhancement Routines presents teachers with a structure of how to think and coordinate content, how to explain texts and topics, and how to teach complex concepts in a way that students are able to gain a substantial understanding of their course work and important information (pg. 39).

\section{Results}

The results are broken down into four groups: pre-group teacher profiles, pre-group teacher candidate profiles, post-group teacher profiles, and post-group teacher candidate profiles. Percentile scores for this questionnaire were recorded. According to Measuring Implementation in Schools: The Stages of Concern Questionnaire (2006), percentile scores for the results of the SOCQ can be displayed in different kinds of tables to allow the researcher or administrator to distinguish the most prevalent concerns within the groups. The most common form of this for the SOCQ is a profile. For our use, profiles are line graphs that display the data collected for each Stage of Concern to create a visual representation of the average percentile scores for each group of participants. Figure 1.1 and 1.2 depict a graphical representation of our results. This study looked at teachers before professional development and after professional development, and also looked at teacher candidates versus teachers with some teaching experience. Percentile scores of the teachers and teacher candidates were collected and averaged. It is important to note that the SOC is a developmental process. This does not mean that all teachers are at the same point in the change process, or that they experience change at the same rate. That is why averages are recorded. Lower percentages in a beginning stage (0-4) implies that there is less concern as there are less answered questions that fall into the lower stages. Higher percentages in the later stages (5-6) imply that there are more questions answered that prescribe to less concern with implementation and effectiveness. This study focuses on the decrease of the percentages in the earlier stages (0-4) as that represents a decrease in the amount of concern had by the teacher and teacher candidates about implementing change in their classrooms.

The first stage or stage 0 of the Stages of Concern is the Awareness stage. The Awareness stage is characterized as a stage where the teacher is not concerned with change, does not have a full concept of the program, and is not interested in implementation. This study found on average, $70 \%$ of teachers scored as high as or higher than their peers on the awareness stage. Teacher candidates scored as high as or higher than their peers $62 \%$ of the time in the Awareness stage. These numbers improved after professional development. Post professional development, $47 \%$ of teachers and $17 \%$ of teacher candidates scored as higher as or higher than their peers in the awareness stage. This is a drastic improvement for this stage of concern after professional development occurred.

Stage 1 is the Informational stage. During this stage there is a beginning interest and a desire to know more about the program or change. In this study, that is Strategic Instruction Model Content Enhancement Routines. On average, pre-professional development teachers scored $90 \%$ and teacher candidates scored 89\%. Post professional development teachers scored $69 \%$ and teacher candidates scored $61 \%$. 
Stage 2 is the personal stage. This is where teachers begin thinking about how the change will directly affect them and their educational effectiveness. On average, pre-professional development teachers scored $84 \%$ and teacher candidates scored $72 \%$. Post professional development they scored $60 \%$ and $60 \%$, respectively.

Stage 3 is the management stage. This is where teachers begin planning implementation and planning for the amount of resources and time needed for implementation. Pre-professional development teachers scored $67 \%$ and teacher candidates scored $43 \%$. Post professional development teachers scored $43 \%$ and teacher candidates scored $25 \%$.

Stage 4 is the consequence stage. This is where teachers are concerned about how the change will directly impact students. Pre-professional development teachers scored 50\% in this stage and teacher candidates scored $27 \%$. Post professional development teachers scored 37\% and teacher candidates scored 38\%.

Stage 5 is the Collaboration stage. This is where teachers begin wanting to share the implementation with others and want to see how they compare to others in implementation. Teachers scored on average $67 \%$ and teacher candidates scored on average $56 \%$ in this stage. Post professional development teachers scored on average $66 \%$ and on average and teacher candidates scored $73 \%$.

The final stage is stage 6 . This is the Refocusing stage where teachers reflect and see what worked and what could be made better. Before professional development, teachers on average scored $41 \%$ and teacher candidates scored $10 \%$. Post professional development teachers scored on average $39 \%$ and teacher candidates $49 \%$.

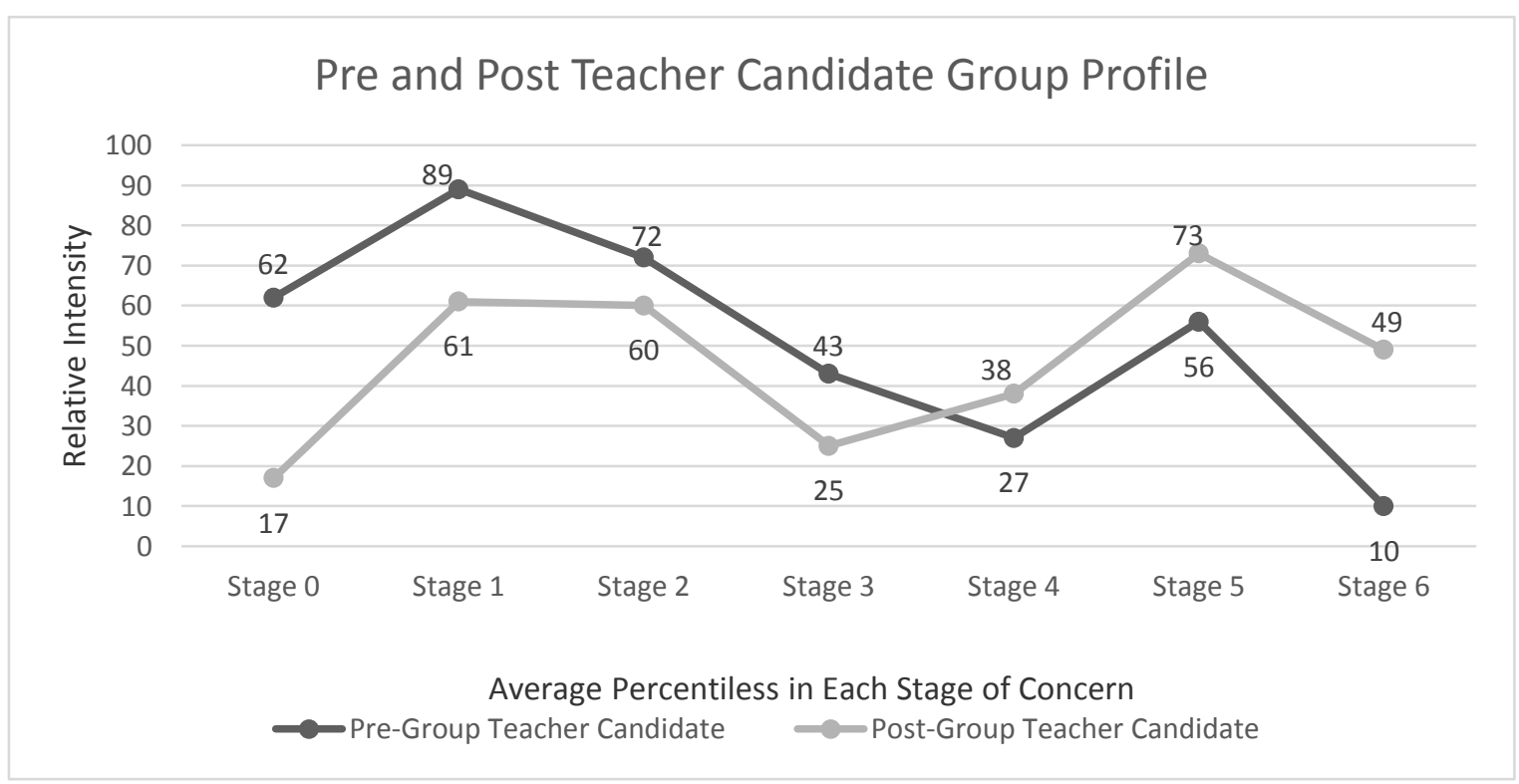

Figure 1 


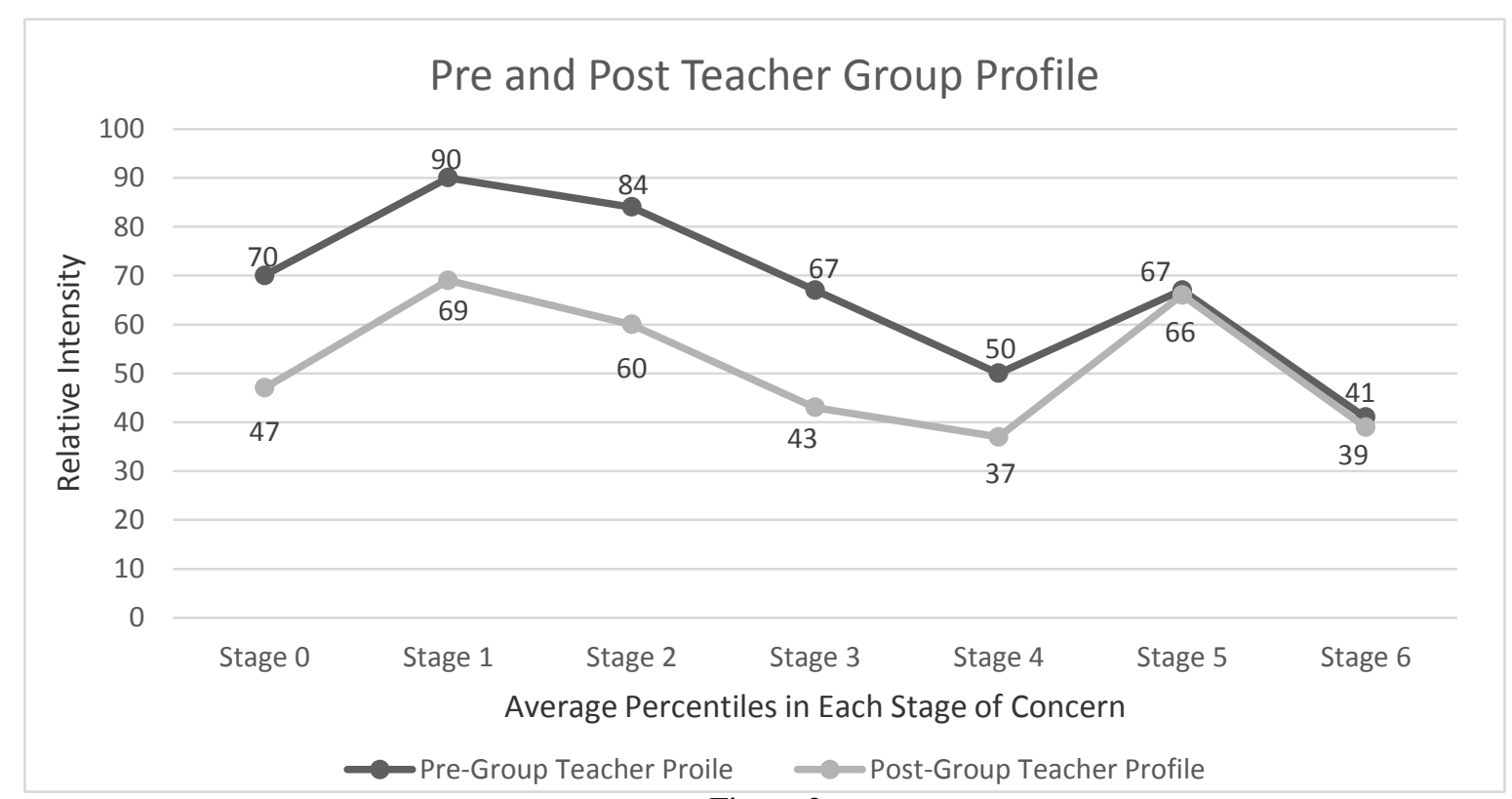

Figure 2

\section{Discussion}

Based on these findings it is reasonable to make the assumption that professional development is effective in lessening aversive feelings of concern surrounding the implementation of new curriculum, or change in teachers and teacher candidates. Thus, the inference can be made that the professional development, specifically Strategic Instruction Model Content Enhancement Routines in this study, had an effect on the teachers' level of concern as determined by the Stages of Concern Questionnaire. It can further be asserted that both teachers and teacher candidates followed similar patterns throughout the PD cycle. Fewer teachers and teacher candidates scored as high on stages 0 (Awareness), 1 (Informational), 2 (Personal), and 3 (Management) at the conclusion of the PD cycle as they did at the beginning of the cycle. Teacher candidates scored higher post PD on 4 (Consequence), 5(Collaboration), and 6(Refocusing). Teacher candidates are in their last year of teacher training, and are close to entering the field. It is our opinion that their concerns in these later stages are a natural extension of their already established concerns about the consequences of their actions in the classroom as they enter into the field unsupervised for the first time.

It is interesting to note that the teachers did not change much in levels 5 (Collaboration) or 6 (Refocusing), during the course of the professional development. Teacher candidates demonstrated, on average, a greater difference between pre- and post-PD on stages 0(Awareness), 1(Informational), 5(Collaboration) \& 6 (Refocusing). For stages 1 and 2, teacher candidates are assimilating new information constantly and may conceptualize change more easily and readily than teachers. On stage 5 , one possible reason for the difference could be that the teachers who participated in the study represented several grade levels, subjects, and schools, indicating possible challenges for specific collaboration efforts. On the other hand, the teacher candidates represented a cohort, and collaboration was a practice engaged in to a higher degree, based on the candidates' university and school experiences. For stage 6, teacher candidates may have scored higher on refocusing than teachers because teacher candidates do not have experience with real classes and students may be refocusing regarding abstract ideas rather that with actual classes.

The limitations of this study primarily have to do with the small sample size. Small sample sizes can affect the reliability of findings. Reliability is typically regarded as the extent to which an assessment tool or research finding produces steady and consistent results. The question is often asked, "If replicated, will these same findings be found?" While this study provides a basis for surveying the effectiveness of professional development when addressing concern surrounding implementation and change with both teachers and teacher candidates, future research may attempt to create a larger sample size to ensure a more comfortable level of reliability and generalizability. For future research purposes, it may also be useful to balance the sample size between teachers and teacher candidates, as this study contained more of one category than the other.

This study looked at the Strategic Instruction Model of Content Enhancement Routines. Future research should look 
at the implications of these findings on other models and curriculum methods, and across a variety of educational settings. In addition, it is recommended that the SOCQ be administered multiple times throughout the PD cycle, and after sufficient time has elapsed so that a truer picture of the effectiveness of the implementation throughout might be observed.

\section{Conclusion}

Professional development has long been associated with improvement in student achievement. In addition, effective professional development can address the specific concerns of teachers who are in the process of implementing a new or different intervention. When those who provide professional development to teachers or teacher candidates address specific concerns of participants by responding to their concerns, PD can have a potentially stronger impact on student outcomes. The current study sought to track changes in the stages of concern with educators through a PD cycle of instruction. What is of greater importance, is how the professional development provided ultimately affects student achievement. Effective professional development is critical when implementing any kind of change, and it is natural for teachers to have concerns about something that is new. This study reinforces the notion that those who provide professional development must be in touch with those who receive professional development in order to generate the best results for those most impacted by PD, the students themselves.

\section{References}

Akiba, M., \& Liang, G. (2016). Effects of teacher professional learning activities on student achievement growth. The Journal of Educational Research, 109(1), 99-110. https://doi.org/10.1080/00220671.2014.924470

Charalambous, C., \& Philippou, G. (2010). Teachers' concerns and efficacy beliefs about implementing a mathematics curriculum reform: Integrating two lines of inquiry. Educational Studies in Mathematics, 75, 1-21. https://doi.org/10.1007/s10649-010-9238-5

Christesen, E., \& Turner, J. (2014). Identifying teachers attending professional development by their stages of concern: Exploring attitudes and emotions. Teacher Educator, 49(4), 232-246. https://doi.org/10.1080/08878730.2014.933641

Common Core State Standards Initiative. (2017) Read the Standards. Retrieved from http://www.corestandards.org/read-the-standards/

George, A.A., Hall, G.E., \& Stiegelbauer, S.M. (2006). Measuring implementation in schools: The Stages of Concern Questionnaire. SEDL: American Institutes for Research.

Holloway, K. (2003). A measure of concern: Research-based program aids innovation by addressing teacher concerns. Tools for Schools. National Staff Development Council.

Knight, J. (2007). Instructional coaching: A partnership approach to improving instruction. Thousand Oaks, CA: Corwin.

Kohler-Evans, P., Calhoon, R., \& Cooper, M. (2014). Effective school practices: Interventions made to last. Journal of the Effective Schools Project, XXI, 24-29.

Kutaka, T. T., Smith, W. M., Albano, A. D., Edwards, C. P., Ren, L., Beattie, H. L., \& Stroup, W. W. (2017). Connecting teacher professional development and student mathematics achievement. Journal of Teacher Education, 68(2), 140-154. https://doi.org/10.1177/0022487116687551

Long, A.F., \& Constable, H. (1991). Using the Stages of Concern Model to assess change over time. British Journal of In-Service Education, 17(2), 100-105. https://doi.org/10.1080/0305763910170203

Martin, J. J., McCaughtry, N., Hodges-Kulinna, P., \& Cothran, D. (2008). The influences of professional development on teachers' self-efficacy toward educational change. Physical Education and Sport Pedagogy, 13(2), 171-190. https://doi.org/10.1080/17408980701345683

Miller, R. G., Curwen, M. S., White-Smith, K. A., \& Calfee, R. C. (2015). Cultivating primary students' scientific thinking through sustained teacher professional development. Early Childhood Education Journal, 43(4), 317-326. https://doi.org/10.1007/s10643-014-0656-3

Saunders, R. R. (2012). Assessment of professional development for teachers in the vocational education and training sector: An examination of the Concerns Based Adoption Model. Australian Journal of Education (ACER Press), 56(2), 182-204.

Strategic Instruction Model in Support of Secondary Literacy. (2011). The University of Kansas Center for Research and Learning. Retrieved from https://sim.drupal.ku.edu/sim-curricula 